\title{
Compact Broadband Dual ZOR Antenna for Multiband Smart Mobile Phone Applications
}

\author{
Jeong Keun Ji \\ Research and Development Center, EMW Co., Ltd., 169-16 Gasan Digital 2-ro, Geumcheon-gu, Seoul 08500, Republic of Korea \\ Correspondence should be addressed to Jeong Keun Ji; hyatlas@emw.co.kr
}

Received 5 March 2017; Accepted 2 May 2017; Published 24 May 2017

Academic Editor: Paolo Baccarelli

Copyright (C) 2017 Jeong Keun Ji. This is an open access article distributed under the Creative Commons Attribution License, which permits unrestricted use, distribution, and reproduction in any medium, provided the original work is properly cited.

\begin{abstract}
A compact broadband dual zeroth-order resonator (ZOR) antenna is proposed for multiband smart mobile phone applications. The theory of broadband zeroth-order mode and multimode technique is used to design the proposed antenna covering GSM850 (824-894 MHz), GSM900 (880-960 MHz), DCS1800 (1710-1880 MHz), PCS1900 (1850-1990 MHz), W2100 (1920-2170 MHz), LTE2300 (2300-2400 MHz), LTE2600 (2500-2690 MHz), and Wi-Fi (2400-2500 MHz) bands. In order to achieve broadband operations, the proposed antenna consists of a large ZOR and a small ZOR that can generate and merge resonant frequencies of the negative-order, zeroth-order, and positive-order modes. The overall size of the antenna is $40 \mathrm{~mm} \times 6 \mathrm{~mm} \times 3 \mathrm{~mm}$. The performance of the antenna is verified by both full-wave simulations and experiments. The measured impedance bandwidths of $3: 1$ VSWR in the low and high bands are $210 \mathrm{MHz}(0.81-1.02 \mathrm{GHz})$ and $1170 \mathrm{MHz}(1.69-2.86 \mathrm{GHz})$, respectively. The antenna provides omnidirectional radiation patterns and measured radiation efficiencies exceeding $43.3 \%$ and $47.5 \%$ for low and high bands, respectively. The antenna performance applied to the commercial smart mobile phone device is also presented. The measured results show that it has the active performance of good total radiated power, total isotropic sensitivity, and specific absorption rate, which can meet the requirement of the smart mobile phone.
\end{abstract}

\section{Introduction}

Recently, there has been a great demand for compact built-in antennas that have small size with broad bandwidth, multiband operation, and good radiation performance because of the rapid development of modern wireless communication systems such as $2 \mathrm{G}, 3 \mathrm{G}$, long term evolution (LTE), LTE-Advanced, and Wi-Fi. Conventional planar inverted-L antennas (PILAs) and planar inverted-F antennas (PIFAs) are widely used as built-in antennas for smart mobile phones [1, 2]. However, due to the limited available volume that could be allocated for the built-in antenna, it is very difficult to achieve multiband and broadband operation for the conventional antennas.

The metamaterial (MTM) is artificially engineered material with unique electromagnetic properties, such as antiparallel phase and group velocities and zero propagation constant at specific nonzero frequency [3, 4]. In particular, various double-negative (DNG), epsilon-negative (ENG), and mu-negative (MNG) composite right/left-handed transmission line (CRLH-TL) structures provide a conceptual design method for implementing zeroth-order resonator (ZOR) antennas [5-10]. In recent years, various ZOR antennas using the CRLH-TL structure have been introduced for mobile phone applications [11-15]. Although these CRLH-TL ZOR antennas provide the advantage of multiband antenna design and size reduction, they typically suffer from narrow bandwidth which could not fully cover multiband and broadband for 2G, 3G, LTE, and Wi-Fi operations.

In this study, a compact broadband dual ZOR antenna is proposed for multiband smart mobile phone applications. By using the theory of broadband zeroth-order mode and multimode technique, the proposed antenna can work covering GSM850 (824-894 MHz), GSM900 (880-960 MHz), DCS1800 (1710-1880 MHz), PCS1900 (1850-1990 MHz), W2100 (1920-2170 MHz), LTE2300 (2300-2400 MHz), LTE2600 (2500-2690 MHz), and Wi-Fi $(2400-2500 \mathrm{MHz})$ bands. The proposed antenna comprises a large ZOR (LZOR) 


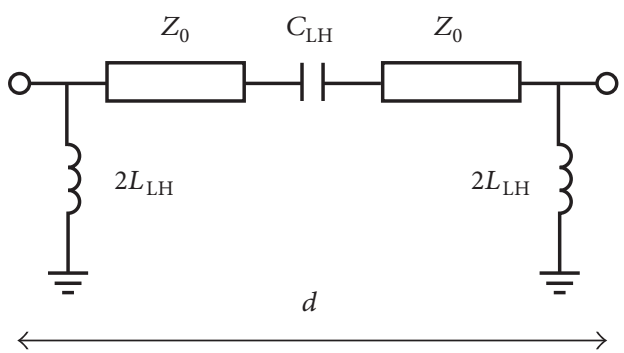

Figure 1: Equivalent circuit model for the ideal CRLH-TL unit cell.

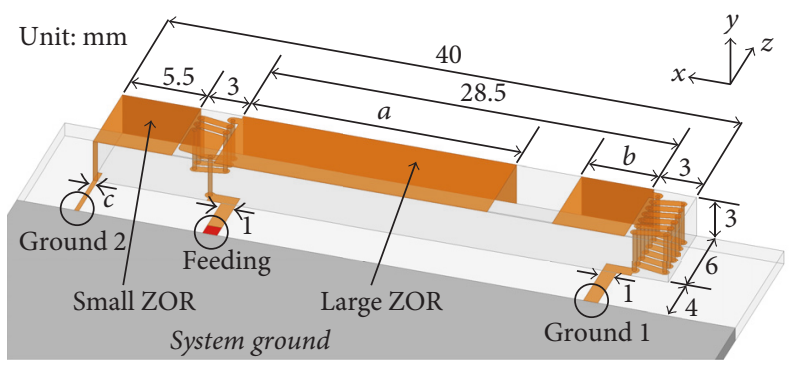

(a)

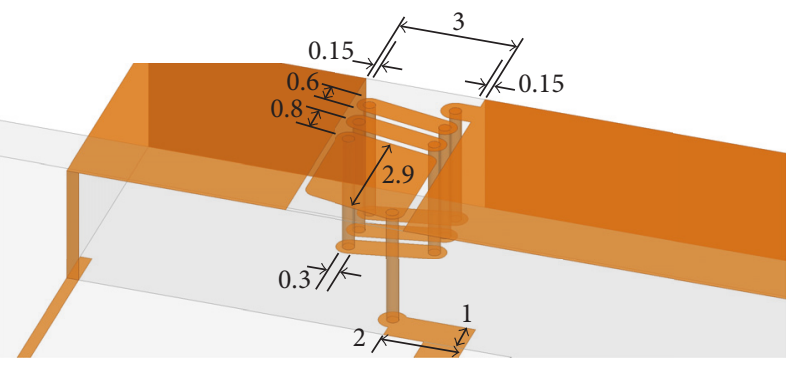

(b)

FIGURE 2: (a) Geometry of the proposed compact broadband dual ZOR antenna. (b) Detailed dimensions of the helix feed line ( $a=19 \mathrm{~mm}$, $b=5 \mathrm{~mm}$, and $c=0.3 \mathrm{~mm}$ ).

and a small ZOR (SZOR) whose broadband characteristics are achieved by merging negative-order, zeroth-order, and positive-order resonant frequencies. Details about these studies are provided in the following sections.

\section{Design Considerations}

An equivalent circuit model for an ideal CRLH-TL unit cell is represented as the combination of a $\mathrm{LH}$ series capacitor $C_{\mathrm{LH}}$, LH shunt inductor $L_{\mathrm{LH}}$, and conventional RH-TL, as shown in Figure 1. The conventional RH-TL with characteristic impedance $Z_{0}$ and physical length $d$ has intrinsic series inductor $L_{\mathrm{RH}}$ and shunt capacitor $C_{\mathrm{RH}}$. In order to generate broadband ZOR, the dispersion curve of the $\mathrm{LH}$ and $\mathrm{RH}$ region must be designed to have a gentle slope. As the value of $C_{\mathrm{LH}}$ becomes smaller, the resonant frequencies of the negative-order modes are increased, whereas those of the positiveorder modes are decreased [16]. Moreover, the bandwidths of the zeroth-order and positive-order modes are extended by introducing large value of $L_{\mathrm{LH}}$ and small value of $C_{\mathrm{RH}}$ [17]. Consequently, the broadband performance of the dual ZOR antenna can be accomplished by merging these resonant frequencies of the negative-order, zeroth-order, and positiveorder modes.

The proposed antenna is designed based on broadband dual ZOR. It is fabricated on a $40-\mathrm{mm}$ long, 6-mm wide, and $3-\mathrm{mm}$ thick FR4 substrate whose relative permittivity is 4.4 and loss tangent is 0.024 . The system circuit board is also fabricated on the FR4 substrate with the dimension of $50 \mathrm{~mm} \times 100 \mathrm{~mm} \times 0.8 \mathrm{~mm}$. The dimensions of the system ground plane and the nonground region are $50 \mathrm{~mm} \times 90 \mathrm{~mm}$ $\times 0.8 \mathrm{~mm}$ and $50 \mathrm{~mm} \times 10 \mathrm{~mm} \times 0.8 \mathrm{~mm}$, respectively. The geometry of the antenna is illustrated in Figure 2. The LZOR is composed of a large folded plate with a gap and two helix lines. The SZOR consists of a small folded plate, a helix line, and a vertical strip line. The configuration provides two LH series capacitors, resulting from the gap on the large folded plate and the coupling gap between the helix feed line and the small folded plate. At the same time, the helix lines and the vertical strip line provide the LH shunt inductors. The folded plates act like the conventional RH-TL with series inductors and shunt capacitors. The helix lines and the vertical strip line affect the zeroth-order resonant frequencies for GSM900 and DCS1800 bands, respectively. The gap on the large folded plate affects the first-negative-order resonant frequency for GSM850 band. Finally, the loop path from the feeding to the ground 1 through the helix lines affects the higher order resonant frequencies for PCS1900, W2100, LTE2300, LTE2600, and Wi-Fi bands.

Figure 3 shows the simulated VSWR of the proposed antenna with variations of the gap on the large folded plate and the vertical strip line. The antenna was simulated by using ANSYS HFSS full-wave simulator. As the gap on the large folded plate is changed from 4.5 to $7.5 \mathrm{~mm}$, the firstnegative-order resonant frequency is shifted from 0.78 to $0.86 \mathrm{GHz}$. However, the zeroth-order resonant frequency in the low band is hardly varied at $0.92 \mathrm{GHz}$. As the width of the vertical strip line is varied from 0.3 to $1 \mathrm{~mm}$, the zeroth-order resonant frequency in the high band is shifted from 1.78 to $1.96 \mathrm{GHz}$. However, the higher order resonant frequencies are 


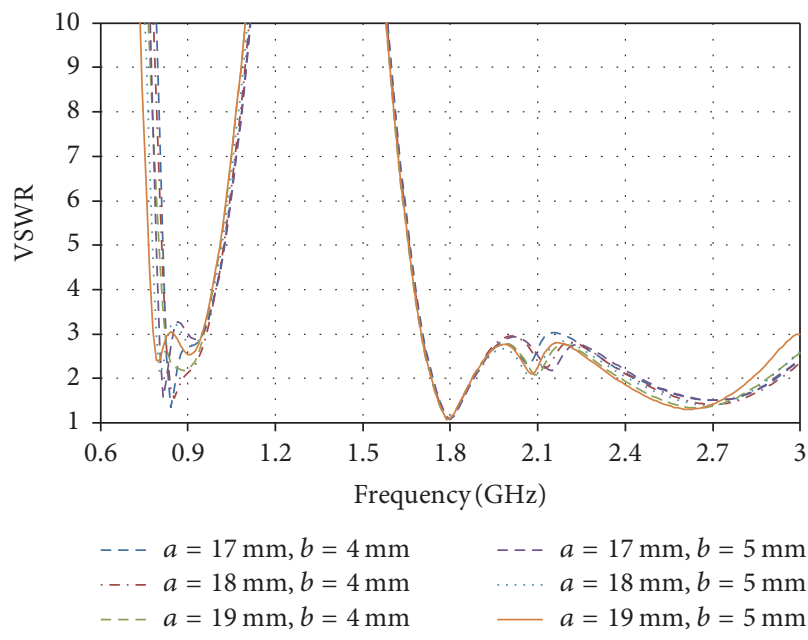

(a)

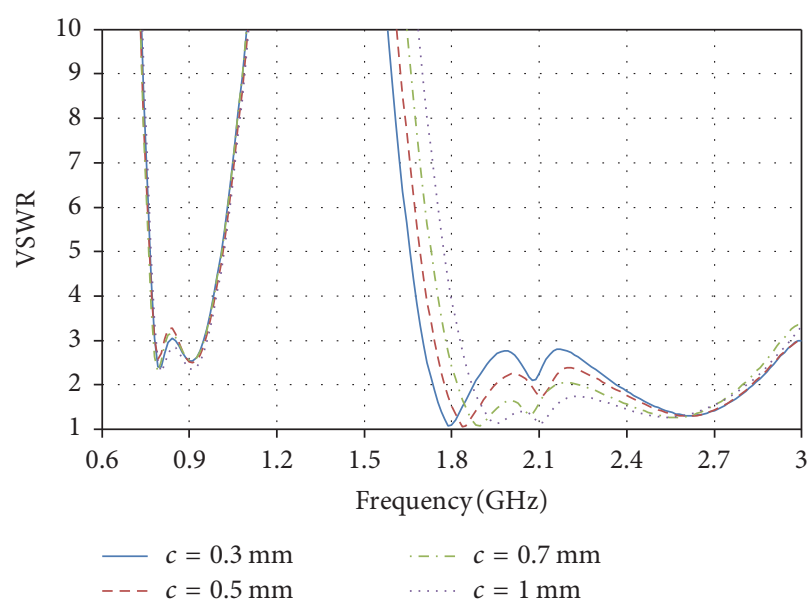

(b)

FIGURE 3: Simulated VSWR of the proposed antenna with variations of (a) the gap on the large folded plate and (b) the vertical strip line.

hardly varied at 2.08 and $2.62 \mathrm{GHz}$, respectively. Thus, the bandwidth enhancement of the proposed antenna is accomplished by merging these resonant frequencies of the low and high bands.

The surface current distributions of the proposed antenna at each resonant frequency were analyzed and shown in Figure 4. Most of the surface currents at 0.82 and $0.92 \mathrm{GHz}$ concentrate on the helix feed line and helix line because of the first-negative-order and zeroth-order resonant mode of the LZOR. Most surface current at $1.78 \mathrm{GHz}$ is formed along the helix feed line and vertical strip line due to the zeroth-order resonant mode of the SZOR. At 2.08 and $2.62 \mathrm{GHz}$, relative strong surface currents exist around the helix line and helix feed line, respectively, due to the higher order resonant modes of the LZOR.

\section{Experimental Results}

Figure 5 shows the fabricated prototype antenna, and the simulated and measured VSWR of the antenna are shown in Figure 6. The measured results were obtained using KEYSIGHT E5071C vector network analyzer. According to the measured results, the zeroth-order resonant frequencies were 0.94 and $1.82 \mathrm{GHz}$ in the low and high bands, respectively. The first-negative-order resonant frequency in the low band was $0.84 \mathrm{GHz}$, and the higher order resonant frequencies in the high band were 2.1 and $2.4 \mathrm{GHz}$. In addition, the measured impedance bandwidths (3:1 VSWR) in the low and high bands were $210 \mathrm{MHz}(0.81-1.02 \mathrm{GHz})$ and $1170 \mathrm{MHz}$ $(1.69-2.86 \mathrm{GHz})$, corresponding to approximately $22.95 \%$ and $51.43 \%$ fractional bandwidths, respectively. The slight difference between the simulated and measured results was observed. This is mainly due to the fabrication tolerance resulting from the structural parameters such as the helix line, coupling gap, and FR4 substrate.

The measured radiation gain patterns of the fabricated antenna at $0.84,0.94,1.82,2.1,2.4$, and $2.69 \mathrm{GHz}$ are plotted in Figure 7. The radiation patterns in $x-y$ plane were nearly omnidirectional characteristics as a dipole antenna. The measured peak gains at $0.84,0.94,1.82,2.1,2.4$, and $2.69 \mathrm{GHz}$ were $0.21,0.69,1.63,0.95,2.59$, and $1.62 \mathrm{dBi}$, respectively. The measured radiation efficiency was $45.8 \%$ at $0.84 \mathrm{GHz}, 52.9 \%$ at $0.94 \mathrm{GHz}, 68.8 \%$ at $1.82 \mathrm{GHz}, 53.2 \%$ at $2.1 \mathrm{GHz}, 68.5 \%$ at $2.4 \mathrm{GHz}$, and $59.4 \%$ at $2.69 \mathrm{GHz}$. The measured radiation efficiency and peak gain over the operating bands are shown in Figure 8. The peak gain varied from -0.27 to $1.23 \mathrm{dBi}$ in the low band and from 0.28 to $2.96 \mathrm{dBi}$ in the high band. The radiation efficiencies were above $43.3 \%$ and $47.5 \%$ in the low and high bands, respectively.

The proposed antenna applied to the commercial smart mobile phone device was also studied. The device can work covering GSM850, GSM900, DCS1800, PCS1900, and W2100 bands. The antenna was equipped at the bottom of the device, and the antenna area is shown in Figure 9. The size of the device was $58 \mathrm{~mm} \times 115 \mathrm{~mm} \times 14 \mathrm{~mm}$. The active performances of the proposed antenna and the original antenna of the device such as total radiated power (TRP), total isotropic sensitivity (TIS), and specific absorption rate (SAR) were measured and compared. The TRP and TIS were measured in an anechoic chamber, and the SAR (1 g SAR) was measured using SPEAG DASY4 SAR measurement system. The $1 \mathrm{~g}$ SAR limit is $1.6 \mathrm{~mW} / \mathrm{g}$ in a $1 \mathrm{~g}$ average mass in the shape of a cube. The antenna input powers of GSM850, GSM900, DCS1800, PCS1900, and W2100 bands were 33, 33, 30, 30, and $23 \mathrm{dBm}$, respectively. The measured TRP and TIS in free space, with a hand phantom, and with a head phantom at each operating band are presented in Table 1. The measured SAR values with the left and right head phantoms at each operating band are also shown in Table 1.

Figure 10 shows a comparison of the measured TRP, TIS, and SAR values of the proposed antenna and the original antenna of the device. For all five bands, the TRP and TIS of the proposed antenna were equal to or better than those of the original antenna. The SAR values of the proposed antenna 


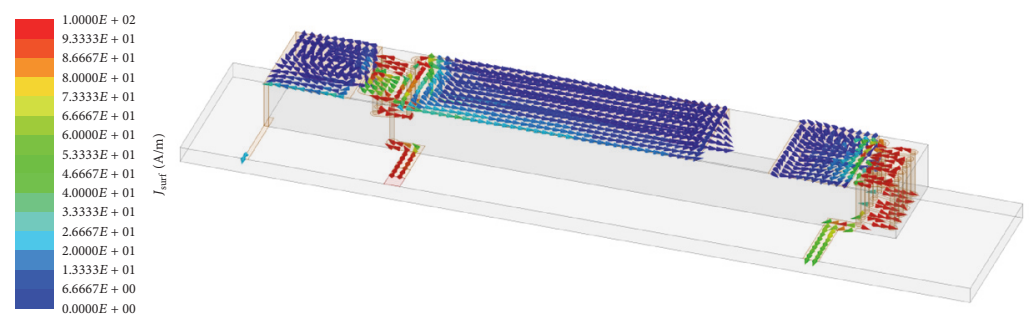

(a)
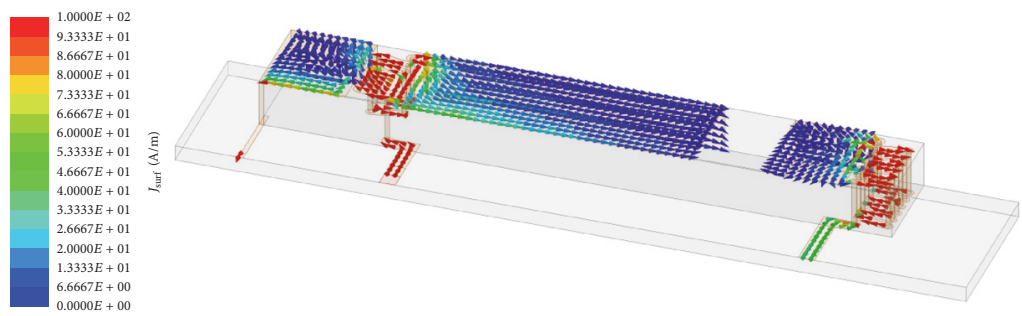

(b)
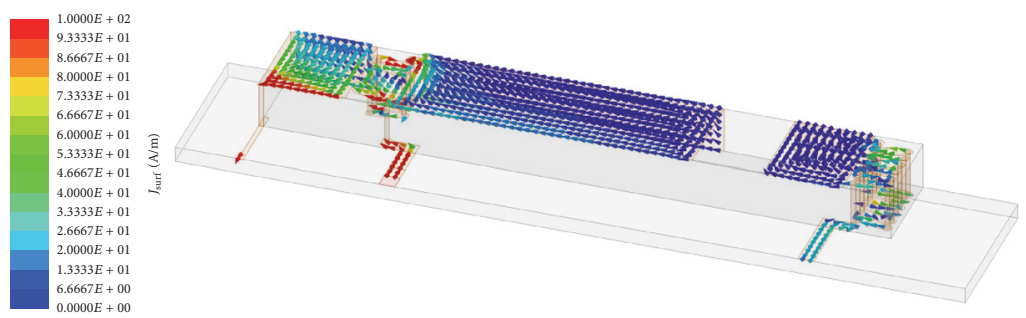

(c)
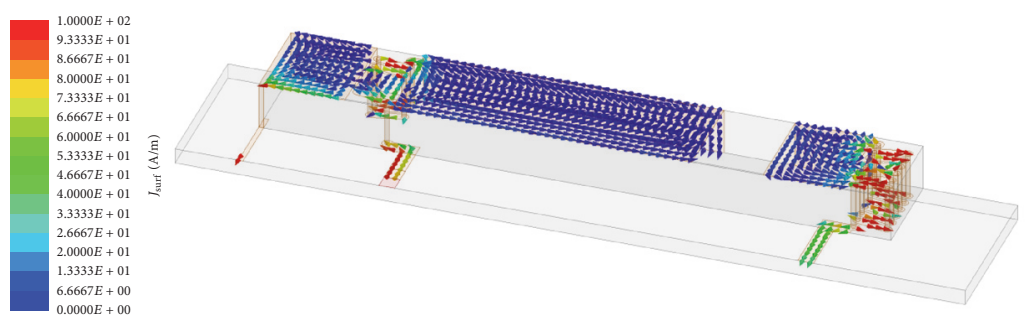

(d)
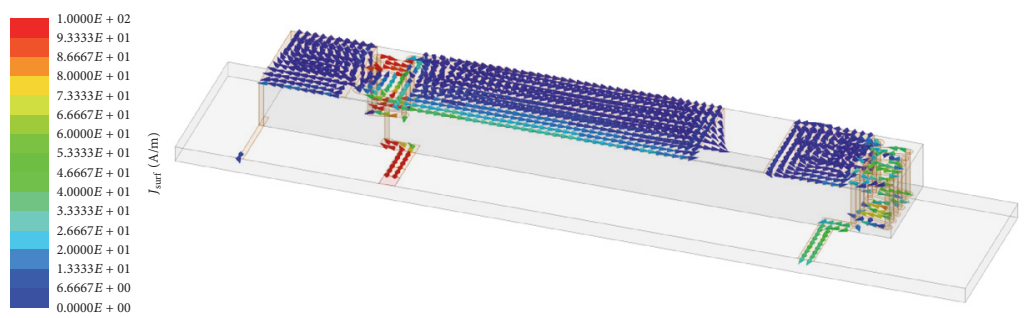

(e)

FIGURE 4: Simulated surface current distributions of the proposed antenna at (a) 0.82 , (b) 0.92 , (c) 1.78 , (d) 2.08 , and (e) $2.62 \mathrm{GHz}$.

were higher than that of the original antenna except for W2100 band. The reason is that the head TRP of the proposed antenna is higher than that of the original antenna. Despite the same reason, the SAR values of the proposed antenna in W2100 band were substantially reduced. It seems that the surface currents concentrate on the helix line due to the higher order resonant modes of the LZOR, so that the electromagnetic field of the antenna spreads to the system ground due to changes in the ground condition. The SAR values of the proposed antenna were below $0.88 \mathrm{~mW} / \mathrm{g}$ in all five bands, and considerably lower than the $1 \mathrm{~g}$ SAR limit. This clearly shows that the proposed antenna is less dependent on the ground condition of the device than the conventional antenna structure. Thus, the measured results show that it has the active performance of good TRP, TIS, and SAR, which can meet the requirement of the smart mobile phone. 
TABLE 1: Measured TRP, TIS, and SAR values of the proposed antenna and the original antenna of the device.

\begin{tabular}{|c|c|c|c|c|c|}
\hline Band & GSM850 & GSM900 & DCS1800 & PCS1900 & W2100 \\
\hline \multicolumn{6}{|l|}{ TRP [dBm] } \\
\hline \multicolumn{6}{|l|}{ Free } \\
\hline Original & 25.68 & 27.18 & 24.79 & 26.65 & 20.42 \\
\hline Proposed & 28.53 & 28.72 & 25.68 & 26.70 & 20.60 \\
\hline \multicolumn{6}{|l|}{ Hand } \\
\hline Original & 19.63 & 19.89 & 22.61 & 22.43 & 16.94 \\
\hline Proposed & 22.80 & 24.82 & 23.26 & 23.35 & 17.47 \\
\hline \multicolumn{6}{|l|}{ Head } \\
\hline Original & 21.25 & 23.00 & 20.02 & 22.42 & 17.06 \\
\hline Proposed & 24.17 & 23.57 & 21.70 & 23.52 & 17.51 \\
\hline \multicolumn{6}{|l|}{ TIS [dBm] } \\
\hline \multicolumn{6}{|l|}{ Free } \\
\hline Original & -100.65 & -97.50 & -105.35 & -105.77 & -106.17 \\
\hline Proposed & -102.76 & -103.16 & -105.67 & -105.93 & -106.68 \\
\hline \multicolumn{6}{|l|}{ Hand } \\
\hline Original & -88.01 & -86.80 & -101.49 & -102.00 & -103.11 \\
\hline Proposed & -94.15 & -95.60 & -102.57 & -102.85 & -103.17 \\
\hline \multicolumn{6}{|l|}{ Head } \\
\hline Original & -97.75 & -95.86 & -100.60 & -102.79 & -103.39 \\
\hline Proposed & -97.84 & -97.48 & -102.14 & -103.38 & -103.51 \\
\hline \multicolumn{6}{|l|}{ SAR [mW/g] } \\
\hline \multicolumn{6}{|l|}{ Left } \\
\hline Original & 0.24 & 0.44 & 0.32 & 0.36 & 1.46 \\
\hline Proposed & 0.58 & 0.68 & 0.35 & 0.41 & 0.88 \\
\hline \multicolumn{6}{|l|}{ Right } \\
\hline Original & 0.22 & 0.38 & 0.20 & 0.25 & 0.77 \\
\hline Proposed & 0.52 & 0.62 & 0.25 & 0.34 & 0.76 \\
\hline
\end{tabular}

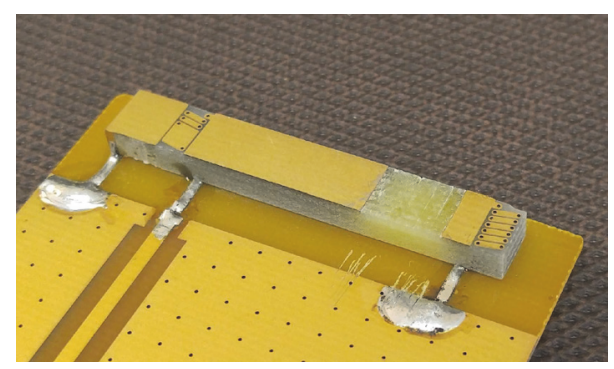

Figure 5: Photograph of the fabricated prototype antenna.

\section{Conclusion}

In this study, a compact broadband dual ZOR antenna was proposed and investigated for GSM850, GSM900, DCS1800, PCS1900, W2100, LTE2300, LTE2600, and Wi-Fi operations. In order to achieve broadband operations, the proposed antenna is composed of a LZOR and a SZOR that can generate and merge resonant frequencies of the negative-order, zerothorder, and positive-order modes. The measured impedance bandwidths of $3: 1$ VSWR in the low and high bands are

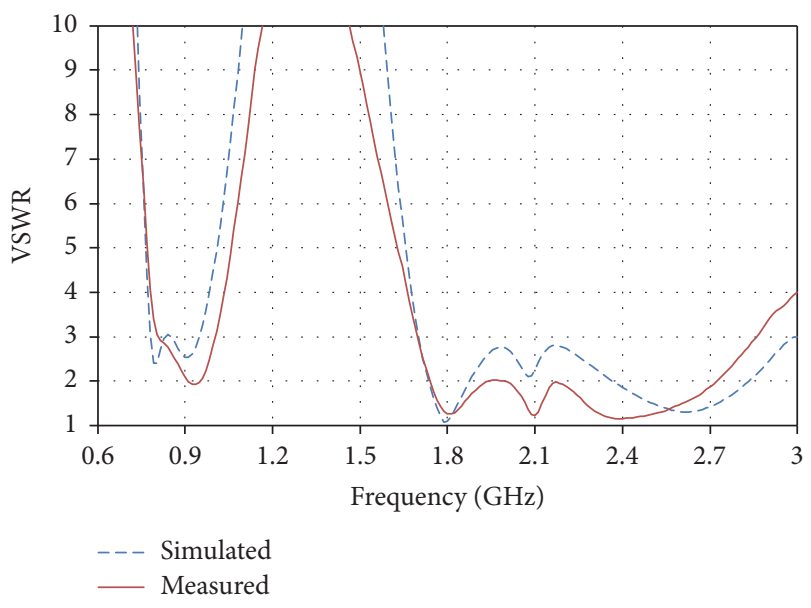

FIGURE 6: Simulated and measured VSWR of the proposed antenna.

$22.95 \%$ and $51.43 \%$, respectively. The antenna provides omnidirectional radiation patterns and measured radiation efficiencies exceeding $43.3 \%$ and $47.5 \%$ for low and high bands, 


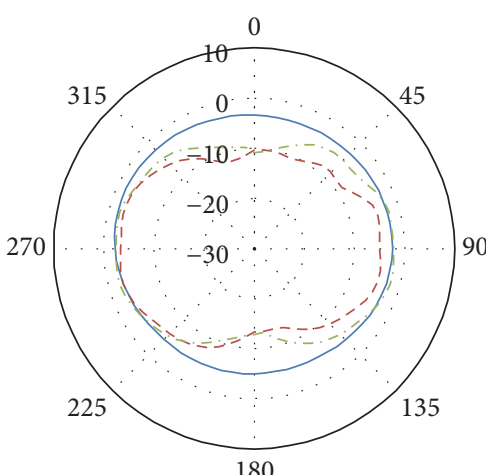

_- $x-y$ plane $-.-y-z$ plane
$-\ldots-z$ plane

(a)

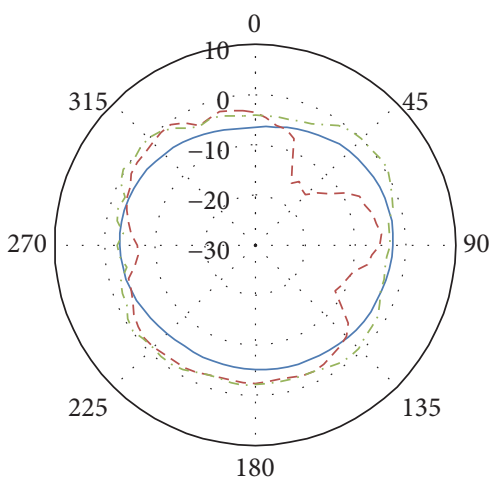

- $x-y$ plane $\ldots y$ - $z$ plane
$-\ldots$ - $z$ plane

(d)

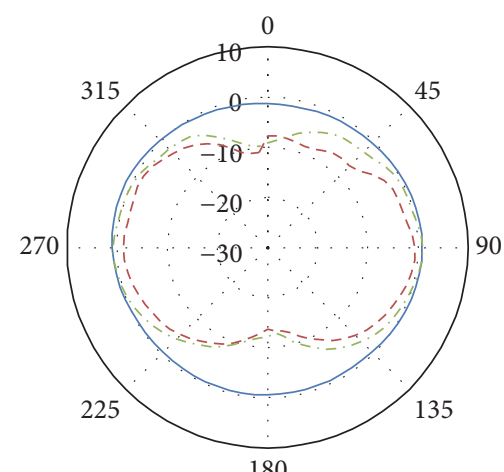

- $x-y$ plane $-.-y-z$ plane - - $x-z$ plane

(b)

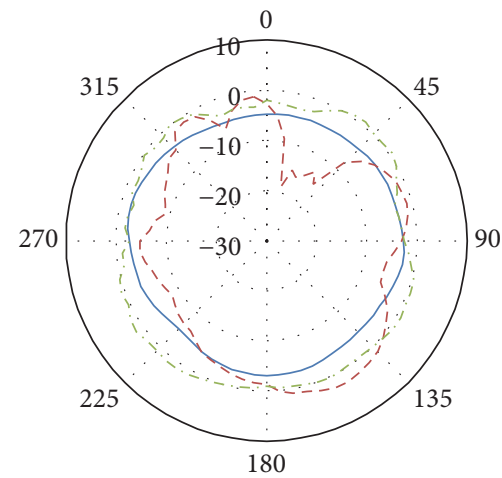

- $x-y$ plane $-.-y-z$ plane
$---x$ - $z$ plane

(e)

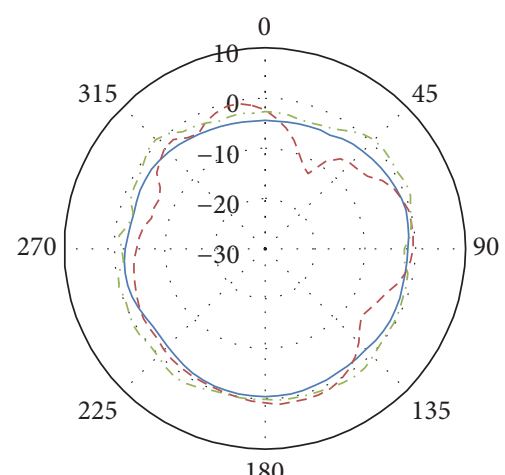

- $x$ - $y$ plane.$---y$ - $z$ plane - - $x$ - $z$ plane

(c)

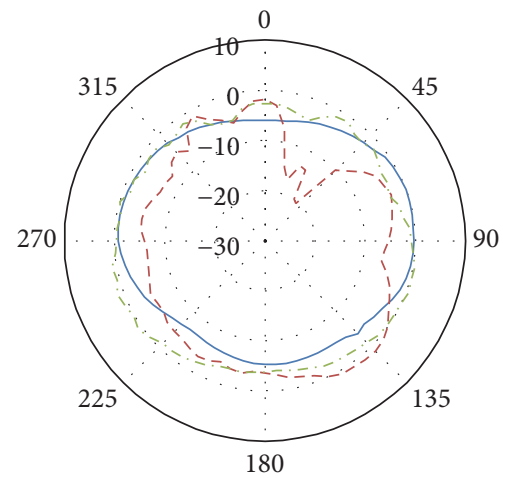

- $x$ - $y$ plane.$--y$ - $z$ plane
$---x$ - $z$ plane

(f)

Figure 7: Measured radiation gain patterns of the proposed antenna at (a) 0.84 , (b) 0.94 , (c) 1.82 , (d) 2.1, (e) 2.4 , and (f) $2.69 \mathrm{GHz}$.

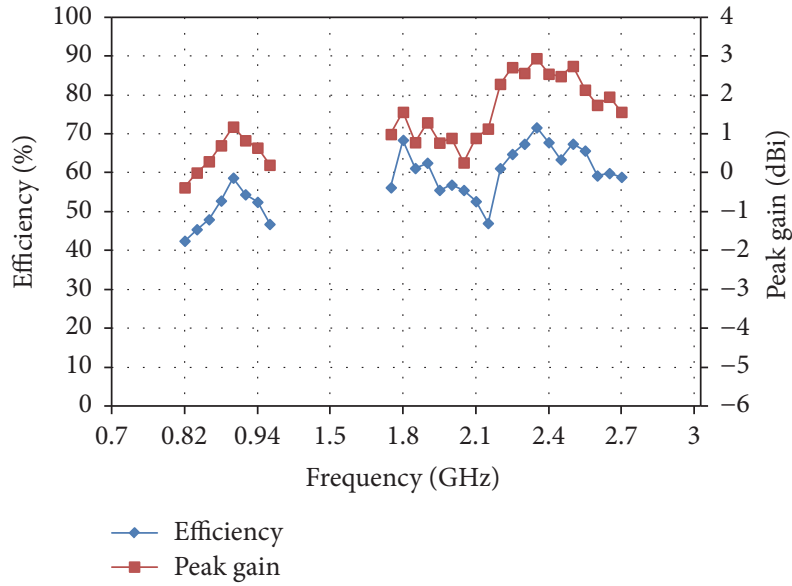

FIGURE 8: Measured radiation efficiency and peak gain of the proposed antenna.

respectively. In addition, the proposed antenna applied to the commercial smart mobile phone device has good active

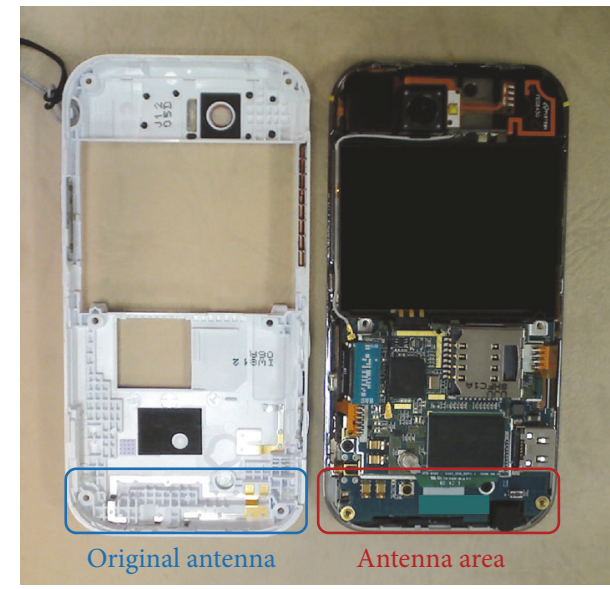

FIgURE 9: Photograph of the commercial smart mobile phone device for the active performance measurement.

performance of TRP, TIS, and SAR, which can meet the requirement of the smart mobile phone. The configuration of 


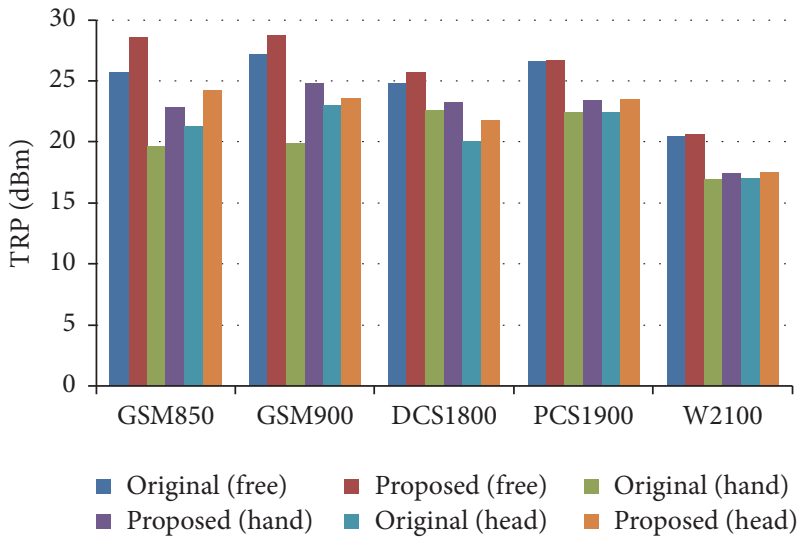

(a)

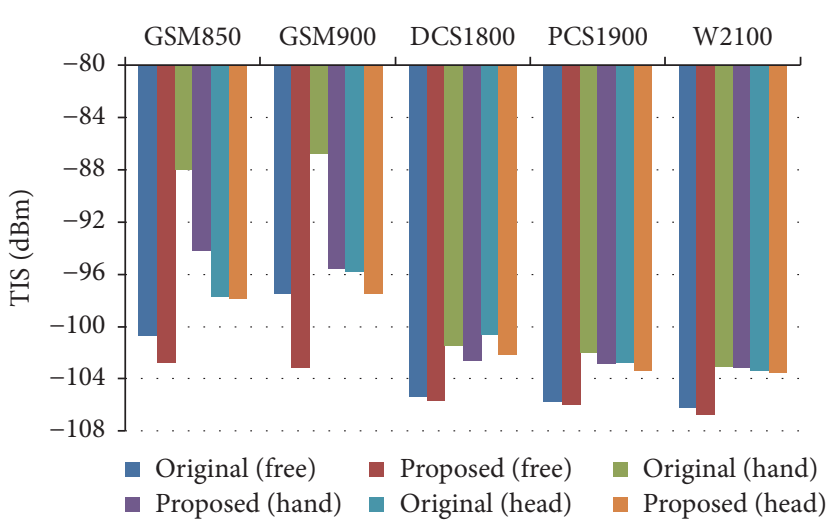

(b)

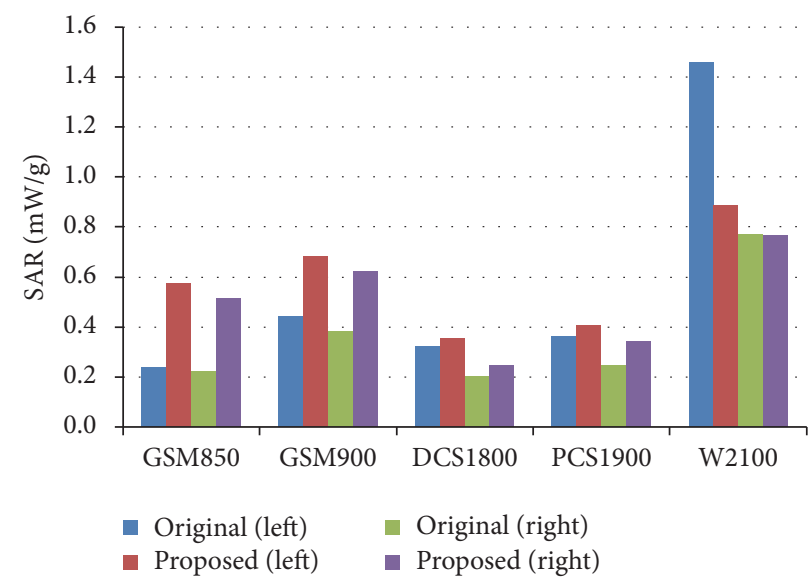

(c)

FIGURE 10: Comparison of the measured active performances of the proposed antenna and the original antenna of the device. (a) TRP. (b) TIS. (c) SAR values.

the antenna is flexible to achieve compact size, good radiation performance, and broadband operation. Therefore, the proposed antenna can be easily integrated in various multiband smart mobile phones and used for multimode wireless communication devices.

\section{Conflicts of Interest}

The author declares that there are no conflicts of interest regarding the publication of this paper.

\section{References}

[1] Z. Zhang, Antenna Design for Mobile Devices, John Wiley \& Sons, Hoboken, NJ, USA, 2011.

[2] D. A. Sanchez-Hernandez, Multiband Integrated Antennas for 4G Terminals, Artech House, Norwood, Mass, USA, 2008.

[3] N. Engheta and R. W. Ziolkowski, Metamaterials: Physics and Engineering Explorations, Wiley, New York, NY, USA, 2006.

[4] C. Caloz and T. Itoh, Electromagnetic Metamaterials: Transmission Line Theory and Microwave Applications: The Engineering Approach, Wiley, New York, NY, USA, 2005.
[5] M. A. Antoniades and G. V. Eleftheriades, "A folded-monopole model for electrically small NRI-TL metamaterial antennas," IEEE Antennas and Wireless Propagation Letters, vol. 7, pp. 425428, 2008.

[6] J.-H. Park, Y.-H. Ryu, J.-G. Lee, and J.-H. Lee, "Epsilon negative zeroth-order resonator antenna," IEEE Transactions on Antennas and Propagation, vol. 55, no. 12, pp. 3710-3712, 2007.

[7] C.-J. Lee, K. M. K. H. Leong, and T. Itoh, "Compact dual-band antenna using an anisotropic metamaterial," in Proceedings of 36th European Microwave Conference, EuMC 2006, pp. 10441047, September 2006.

[8] F. Qureshi, M. A. Antoniades, and G. V. Eleftheriades, "A compact and low-profile metamaterial ring antenna with vertical polarization," IEEE Antennas and Wireless Propagation Letters, vol. 4, no. 1, pp. 333-336, 2005.

[9] A. Sanada, M. Kimura, I. Awai, C. Caloz, and T. Itoh, "A planar zeroth-order resonator antenna using a left-handed transmission line," in Proceedings of the 34th European Microwave Conference, pp. 1341-1344, 2004.

[10] A. Sanada, C. Caloz, and T. Itoh, "Novel zeroth-order resonance in composite right/left-handed transmission line resonators," in Proceedings of the Asia-Pacific Microwave Conference, vol. 3, pp. 1588-1591, 2003. 
[11] J.-G. Lee and J.-H. Lee, "Enhanced bandwidth of dual ZOR antenna for multiband applications," in Proceedings of 10th European Conference on Antennas and Propagation, EuCAP 2016, pp. 1-3, 2016.

[12] L. Li, Z. Jia, F. F. Huo, and W. Q. Han, "A novel compact multiband antenna employing dual-band CRLH-TL for smart mobile phone application," IEEE Antennas and Wireless Propagation Letters, vol. 12, pp. 1688-1691, 2013.

[13] L. Li, F. Huo, Z. Jia, and W. Han, "Dual zeroth-order resonance antennas with low mutual coupling for MIMO communications," IEEE Antennas and Wireless Propagation Letters, vol. 12, pp. 1692-1695, 2013.

[14] J. Kim, "Study on an epsilon-negative zeroth-order resonator antenna properties for mobile handsets," Microwave and Optical Technology Letters, vol. 54, no. 4, pp. 1066-1069, 2012.

[15] C.-J. Lee, W. Huang, A. Gummalla, and M. Achour, "Small antennas based on CRLH structures: concept, design, and applications," IEEE Antennas and Propagation Magazine, vol. 53, no. 2, pp. 10-25, 2011.

[16] J. K. Ji, G. H. Kim, and W. M. Seong, "Bandwidth enhancement of metamaterial antennas based on composite right/left-handed transmission line," IEEE Antennas and Wireless Propagation Letters, vol. 9, pp. 36-39, 2010.

[17] B.-J. Niu, Q.-Y. Feng, and P.-L. Shu, "Epsilon negative zerothand first-order resonant antennas with extended bandwidth and high efficiency," IEEE Transactions on Antennas and Propagation, vol. 61, no. 12, pp. 5878-5884, 2013. 


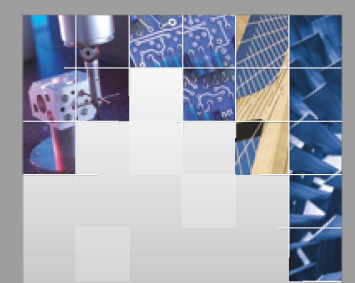

\section{Enfincering}
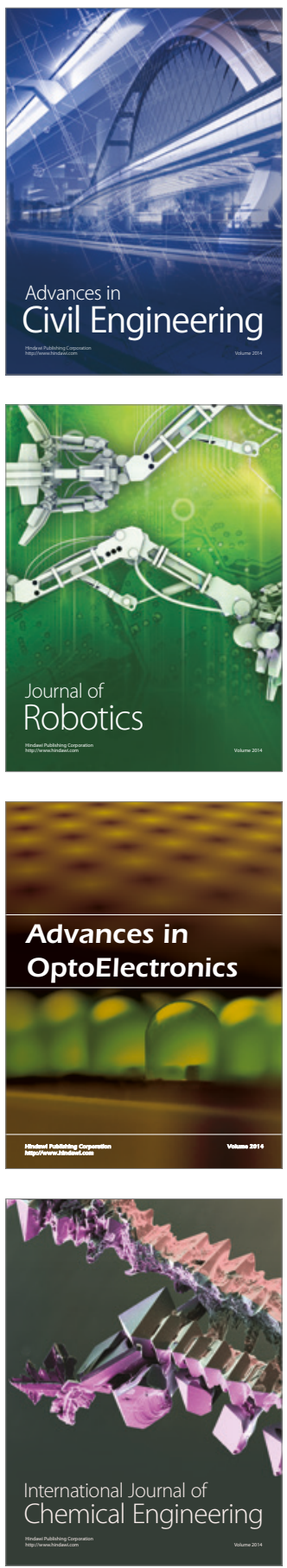

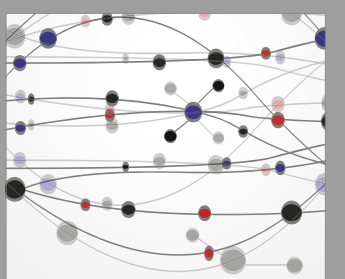

The Scientific World Journal

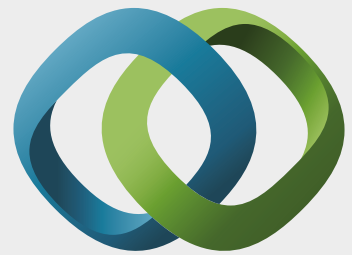

\section{Hindawi}

Submit your manuscripts at

https://www.hindawi.com
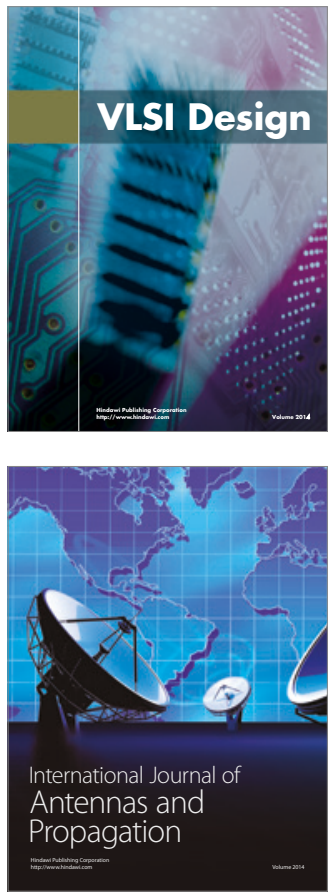

\section{Rotating}

Machinery
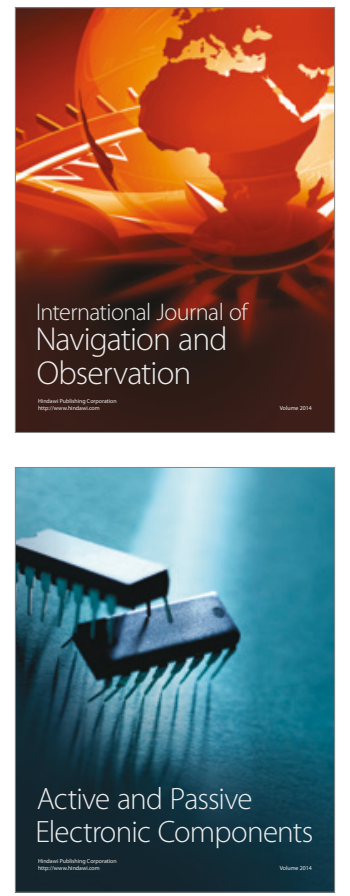
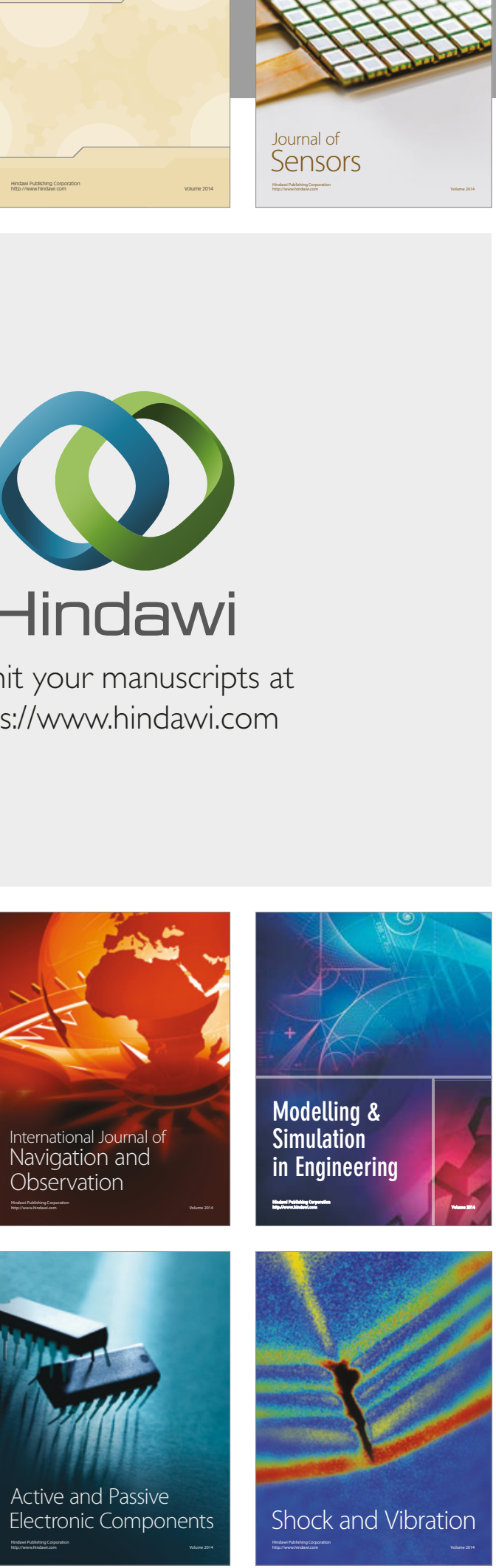
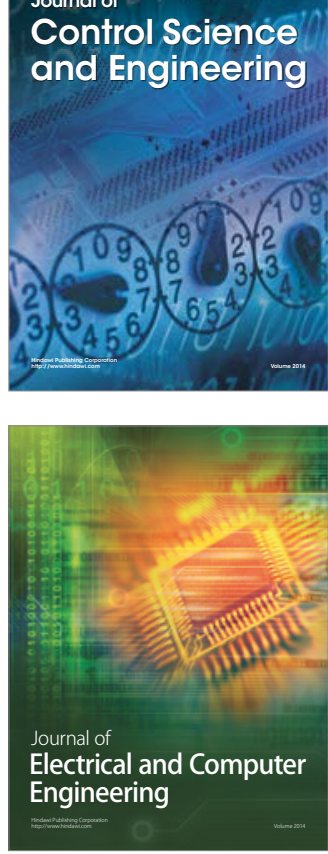

Distributed

Journal of

Control Science

and Engineering
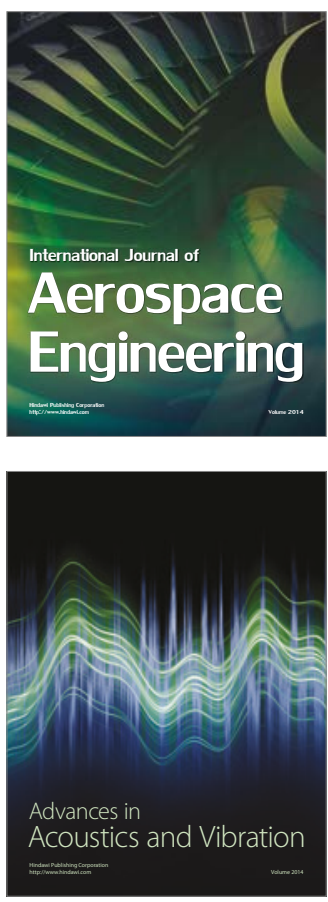

Sensor Networks 